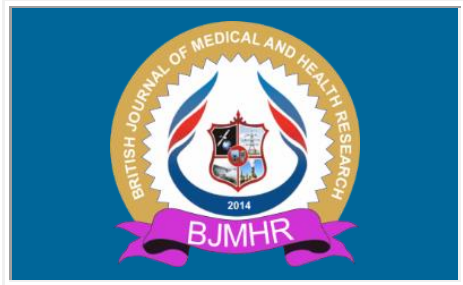

\title{
BJMHR
}

British Journal of Medical and Health Research

Journal home page: www.bjmhr.com

\section{Prevalence and Correlation of Pain in Fatigued Patients with Diabetes in Taif City, Saudi Arabia}

\section{Adnan A Mubaraki ${ }^{1}$ MD, Afnan K Sibyani ${ }^{2 *}$, Ghaida Turki Alrbaiai ${ }^{2}$, Khairiah Y Alqashqari' ${ }^{2}$, Haneen Saad Almalki ${ }^{2}$, Rahaf M Alhulayfi' ${ }^{2}$, Ameera S Baabbad ${ }^{2}$ \\ 1. Department of Medicine, Taif University, Taif, Kingdom of Saudi Arabia. \\ 2. Medical Intern, College of Medicine, Taif University, Taif, Saudi Arabia.}

\section{ABSTRACT}

Diabetes mellitus (DM) is one of the common chronic diseases worldwide. Approximately 422 million people have been diagnosed with DM worldwide; in Saudi Arabia, the prevalence is 30\%. DM has many complications that are known to cause pain and fatigue to the patients. Moreover, chronic pain and fatigue are highly associated with a decreased quality of life. Pain and fatigue studies on diabetic patients are still insufficient in Saudi Arabia especially in Taif city. Thus, the aim of this study is to evaluate the prevalence and correlation of pain in fatigued patients with diabetes in Taif city, Saudi Arabia._A cross-sectional study was conducted from October 2020 to March 2021. The sample size included 200 participants from Taif city. Inclusion criteria encompassed those who were $\geq 15$ years of age and had diabetes for at least one year. Those who did not have diabetes or were younger than 15 years of age were excluded. A self-administrated electronic questionnaire was used to collect the data. The statistical analysis of data was performed using IBM statistics version 20. A total of $55.2 \%$ of the participants reported the presence of pain. Legs and feet were the most frequent locations of the pain. There was association between pain and age, gender, depression, anxiety, and physical activity. In contrast, there was no association between the type of diabetes and fatigue severity or between the type of diabetes and pain severity. Pain is a highly prevalent symptom in diabetic patients. Highlighting the importance of improving modifiable risk factors in diabetic patients is paramount in reducing the effect of pain and fatigue on those patients.

Keywords: Diabetes mellitus, Fatigue, Pain.

*Corresponding Author Email: fnoona-sebyani@hotmail.com

Received 05 May 2021, Accepted 22 June 2021

Please cite this article as: Mubaraki AA et al., Prevalence and Correlation of Pain in Fatigued Patients with Diabetes in Taif City, Saudi Arabia. British Journal of Medical and Health Research 2021. 


\section{INTRODUCTION}

Diabetes mellitus (DM) is a common chronic disorder that a general practitioner treats during clinical practice (1). Approximately 422 million people worldwide have been diagnosed with DM (2), while the overall prevalence in Saudi Arabia is 30\% (3). Pain is the most frequent complaint that may make patients visit a primary healthcare provider (4-6); pain is defined as uncomfortable sensations in the body, and it may be acute or chronic.

Chronic pain is a highly prevalent and disabling symptom among diabetic patients (7). There are many conditions and complications related to DM, which are known to cause pain for the patients. For example, micro vascular complications of DM can cause painful peripheral neuropathy, which affects $16 \%$ of diabetic patients (8).

Furthermore, entrapment neuropathy (e.g., carpal tunnel syndrome and trigger fingers) can be secondary to DM (8). Chronic pain, which is associated with diabetes, is greatly variable and considerably affects patients' lives (9). Pain has been reported by many patients to affect sleep and daily activities and to cause emotional distress (10-12). In addition to diabetes-related complications, pain may contribute to chronic severe disabling fatigue (13), which is strongly correlated with pain in diabetic patients (8).

A Saudi cross-sectional study showed a significant association between diabetes and chronic pain. The most common pain sites among diabetic patients were lower limbs, abdominal area, and neck as reported by $11.1,6.7$, and $4.4 \%$ of the patients, respectively (14). Another recently published study determined that diabetic patients were more prone to develop chronic pain (15).

Menting $\mathrm{J}$ et al. evaluated the prevalence, severity, and location of pain among fatigued diabetic patients. The pain was reported by $72 \%$ of their cohort with female predominance, and fatigue severity was proportionally related to the number of diabetes-related complications (8). A study by Bair MJ determined that pain was strongly associated with poorer mental health and physical activity (16).

Diabetes is one of the most common and growing health problems globally. However, the number of studies on pain and fatigue in diabetic patients is still insufficient in Saudi Arabia, especially in Taif. Therefore, this study aimed to determine the prevalence and correlation of pain in fatigued diabetic patients in Taif city, Saudi Arabia.

\section{MATERIALS AND METHOD:}

A cross-sectional study was conducted from October 2020 to March 2021 with a sample size of 200 participants who were randomly selected from Taif residents. Our study aimed to determine the prevalence of pain in fatigued diabetic patients in Taif city, describe the severity 
and location of the pain, and assess functional impairment in those patients. Ethical approval was obtained from the research ethics committee at Taif University.

The inclusion criteria encompassed all Taif city residents who were $\geq 15$ years old and diagnosed with DM for more than one year. Participants diagnosed with congestive heart failure, renal failure, or visual impairment, and patients with a medical history of stroke in the past five years, or wheelchair dependents, and those with other medical co-morbidity or psychiatric condition that may explain the fatigue were excluded.

Data collection was performed through electronic questionnaires. The questionnaire included yes-no, multiple choice, and rating scale questions. Other information included participants' demographics (i.e., age, gender, and city of residence), presence of DM, and further evaluation regarding diabetes type, duration of the disease, and antidiabetic medication use (i.e., insulin, oral hypoglycemic agent, or both).

Estimation of diabetes control was assessed by the presence of diabetes-related complications (e.g., retinopathy, neuropathy, nephropathy, stroke, and cardiac complications) and last measured HbA1C level. Information about the patients' comorbidities (e.g., arthritis, hypertension, heart diseases, thyroid diseases, renal diseases, stroke, dyslipidemia, depression, anxiety, and cancer) was also collected.

Yes-no questions to assess the presence of pain and, if present, evaluate the location and type of pain were asked. A short form of the McGill pain questionnaire to classify pain character and intensity was obtained from the participants. Fatigue screening and evaluation of concentration, motivation, physical activity, and fatigue-related problems in the past two weeks were assessed using the checklist individual strength (CIS) survey with a score ranging from 8 to 56. High fatigue severity is associated with a high score.

All statistical analyses were performed with IBM statistics version 20. The normality of distribution was assessed using the Kolmogorov-Smirnov test. Data for continuous variables were expressed as the mean $+/-$ SD and median (range). Categorical variables were described as frequency (percentage). Parametric and non-parametric tests were used to determine the association between numeric variables according to distribution normality. A Chi-square test was used to compare categorical variables. The significance level was set at $\leq 0.05$.

\section{RESULTS AND DISCUSSION}

The primary objective of this study was to assess the association between pain and fatigue and diabetes. The demographical data are shown in Table 1. Out of 250 participants in the study, $166(66.4 \%)$ were 40-59 years old. The majority of participants were males, i.e., 142 (56.80\%). Moreover, the most common chronic disease in the study was hypertension (29.2\%), while 
renal disease was least common (4.0\%). Furthermore, $27.6 \%$ of the participants reported exercising once a week (Table 1).

Approximately $48.0 \%$ of the participants have type 2 DM. Regarding the duration of diabetes, $40.8 \%$ of the participants had DM for less than 5 years, and $37.6 \%$ had it for more than 10 years. In addition, $47.2 \%$ of the participants used oral hypoglycemic drugs, and $20.8 \%$ used insulin. A total of $39 \%$ of the patients with pain did not know the level of HbA1c, and in $61.2 \%$ of the patients, the level was less than seven. The most common complications of diabetes in our study were retinopathy (21.6\%) and neuropathy (16.8\%) (Table 1).

Surprisingly, more than half of our participants [i.e., 138 participants (55.2\%)] reported the presence of pain with the mean value on the visual analog scale (VAS) of 5.15 (SD = 2.35). Furthermore, the mean score of fatigue was 70.35 (SD = 36.95) (Table 2). Regarding the location of pain, legs and feet were the most frequent locations for pain (as reported by $38.40 \%$ of the participants), followed by lower back (34.80\%), shoulder, and whole body (28.30\%). The locations with the least pain reported by our patients were chest and upper back $(9.40 \%)$ (Figure 1). Our study determined that out of 138 diabetic patients with pain, 92 (84.4\%) used painkiller medications.

The most frequent character of pain was exhausting pain (reported by 89 of our participants); $23.2 \%$ of the participants had a mild form, $26.8 \%$ - moderate, and $14.5 \%$ - severe. Tender pain was reported by 89 participants; $22.5 \%$ of the participants had a mild form, $32.6 \%$ - moderate, and $9.4 \%$ - severe. In contrast, gnawing pain and sickening were the least common characters of pain that were felt by 45 responders (Table 3 ).

Regarding chronic pain, most of our patients exhibited joint arthritis (46.40\%) followed by peripheral neuropathy and disc herniation in the lower back, $25.40 \%$ and $18.80 \%$, respectively. Disc herniation in the neck was least frequent (5.80\%) (Figure 2).

Our results showed no association between the type of diabetes and fatigue severity $(p=0.470)$ or between the type of diabetes and pain severity $(\mathrm{p}=0.390)$. In addition, the severity of pain and fatigue was not correlated with diabetes duration in years, $(p=0.239)$ and $(p=0.566)$, respectively. There was no relation between HbA1c level and the presence of pain $(\mathrm{p}=0.092)$. In contrast, we determined that there was significant association between age and pain $(\mathrm{p}=$ $0.021)$, gender and pain $(\mathrm{p}=0.058)$, depression and pain $(\mathrm{p}=0.008)$, anxiety and pain $(\mathrm{p}=$ $0.001)$, and physical activity and pain $(\mathrm{p}=0.001)$. Moreover, only neuropathy and retinopathy were significantly associated with pain, $(\mathrm{p}<0.001)$ and $(\mathrm{p}=0.004)$, respectively.

Regarding the pain character, we determined that throbbing pain $(\mathrm{p}=0.003)$, shooting pain $(\mathrm{p}$ $=0.016)$, cramping pain $(\mathrm{p}=0.005)$, aching pain $(\mathrm{p}=0.047)$, and burning pain $(\mathrm{p}=0.057)$ were statistically associated with the HbA1c level. 
Table 1: Demographics and clinical variables of the sample and difference between patients with pain and without pain.

\begin{tabular}{|c|c|c|c|c|}
\hline & $\begin{array}{l}\text { Overall sample } \\
(n=250)\end{array}$ & $\begin{array}{l}\text { Patients without } \\
\text { pain }(n=112)\end{array}$ & $\begin{array}{l}\text { Patients with } \\
\text { pain }(n=138)\end{array}$ & P value* \\
\hline $\begin{array}{l}\text { Age } \\
15-39 \\
40-59 \\
>60\end{array}$ & $\begin{array}{l}39(15.6 \%) \\
166(66.4 \%) \\
45(18.0 \%)\end{array}$ & $\begin{array}{l}25(64.1 \%) \\
71(42.8 \%) \\
16(35.6 \%)\end{array}$ & $\begin{array}{l}14(35.9 \%) \\
95(57.2 \%) \\
29(64.4 \%)\end{array}$ & 0.021 \\
\hline $\begin{array}{l}\text { Gender } \\
\text { Female } \\
\text { Male }\end{array}$ & $\begin{array}{l}108(43.20 \%) \\
142(56.80 \%)\end{array}$ & $\begin{array}{l}41(38.0 \%) \\
71(50.0 \%)\end{array}$ & $\begin{array}{l}67(62.0 \%) \\
71(50.0 \%)\end{array}$ & 0.058 \\
\hline $\begin{array}{l}\text { Type of diabetes } \\
\text { Don't know } \\
\text { Type } 1 \\
\text { Type } 2\end{array}$ & $\begin{array}{l}76(30.4 \%) \\
54(21.6 \%) \\
120(48.0 \%) \\
\end{array}$ & $\begin{array}{l}43(56.6 \%) \\
25(46.3 \%) \\
44(36.7 \%) \\
\end{array}$ & $\begin{array}{l}33(43.4 \%) \\
29(53.7 \%) \\
76(63.3 \%) \\
\end{array}$ & 0.023 \\
\hline $\begin{array}{l}\text { Duration of diabetes } \\
<5 \text { years } \\
5-10 \text { years } \\
>10 \text { years }\end{array}$ & $\begin{array}{l}102(40.8 \%) \\
54(21.6 \%) \\
94(37.6 \%)\end{array}$ & $\begin{array}{l}57(55.9 \%) \\
19(35.2 \%) \\
36(38.3 \%)\end{array}$ & $\begin{array}{l}45(44.1 \%) \\
35(64.8 \%) \\
58(61.7 \%)\end{array}$ & 0.013 \\
\hline $\begin{array}{l}\text { Diabetic medications } \\
\text { None } \\
\text { Insulin } \\
\text { Oral drugs } \\
\text { Both }\end{array}$ & $\begin{array}{l}39(15.6 \%) \\
52(20.8 \%) \\
118(47.2 \%) \\
41(16.4 \%)\end{array}$ & $\begin{array}{l}28(71.8 \%) \\
24(46.2 \%) \\
48(40.7 \%) \\
12(29.3 \%)\end{array}$ & $\begin{array}{l}11(28.2 \%) \\
28(53.8 \%) \\
70(59.3 \%) \\
29(70.7 \%)\end{array}$ & 0.001 \\
\hline $\begin{array}{l}\text { Diabetes complications } \\
\text { Retinopathy, yes } \\
\text { Neuropathy, yes } \\
\text { Cardiac, yes } \\
\text { Nephropathy, yes } \\
\text { Stroke, yes }\end{array}$ & $\begin{array}{l}54(21.6 \%) \\
42(16.8 \%) \\
12(4.8 \%) \\
12(4.8 \%) \\
2(0.8 \%) \\
\end{array}$ & $\begin{array}{l}15(27.8 \%) \\
5(11.9 \%) \\
3(25.0 \%) \\
3(25.0 \%) \\
0(0.0 \%)\end{array}$ & $\begin{array}{l}39(72.2 \%) \\
37(88.1 \%) \\
9(75.0 \%) \\
9(75.0 \%) \\
2(100 \%)\end{array}$ & $\begin{array}{l}0.004 \\
<0.001 \\
0.157 \\
0.157 \\
0.201 \\
\end{array}$ \\
\hline $\begin{array}{l}\text { HbA1C } \\
\text { I don't know } \\
<7 \\
7-10 \\
>10\end{array}$ & $\begin{array}{l}46(18.5 \%) \\
85(34.3 \%) \\
90(36.3 \%) \\
27(10.9 \%) \\
\end{array}$ & $\begin{array}{l}28(60.9 \%) \\
33(38.8 \%) \\
38(42.2 \%) \\
11(40.7 \%)\end{array}$ & $\begin{array}{l}18(39.1 \%) \\
52(61.2 \%) \\
52(57.8 \%) \\
16(59.3 \%)\end{array}$ & 0.092 \\
\hline $\begin{array}{l}\text { Co-morbidity } \\
\text { HTN, yes } \\
\text { Dyslipidemia , yes } \\
\text { Arthritis, yes } \\
\text { Heart diseases, yes } \\
\text { Renal diseases, yes } \\
\text { Thyroid diseases, yes } \\
\text { Depression, yes } \\
\text { Anxiety, yes }\end{array}$ & $\begin{array}{l}73(29.2 \%) \\
66(26.4 \%) \\
61(24.5 \%) \\
27(10.8 \%) \\
10(4.0 \%) \\
24(9.6 \%) \\
28(11.2 \%) \\
49(19.6 \%) \\
\end{array}$ & $\begin{array}{l}22(30.1 \%) \\
16(24.2 \%) \\
7(11.5 \%) \\
7(25.9 \%) \\
1(10.0 \%) \\
7(29.2 \%) \\
6(21.4 \%) \\
12(24.5 \%) \\
\end{array}$ & $\begin{array}{l}51(69.9 \%) \\
50(75.8 \%) \\
54(88.5 \%) \\
20(74.1 \%) \\
9(90.0 \%) \\
17(70.8 \%) \\
22(78.6 \%) \\
37(75.5 \%) \\
\end{array}$ & $\begin{array}{l}0.003 \\
<0.001 \\
<0.001 \\
0.037 \\
0.024 \\
0.105 \\
0.008 \\
0.001 \\
\end{array}$ \\
\hline $\begin{array}{l}\text { Physical activity per week } \\
(\geq \mathbf{3 0} \text { min }) \\
\text { None } \\
\text { Once } \\
2-3 \text { times } \\
>3 \text { times }\end{array}$ & $\begin{array}{l}61(24.4 \%) \\
69(27.6 \%) \\
63(25.2 \%) \\
57(22.8 \%) \\
\end{array}$ & $\begin{array}{l}15(24.6 \%) \\
34(49.3 \%) \\
28(44.4 \%) \\
35(61.4 \%)\end{array}$ & $\begin{array}{l}46(75.4 \%) \\
35(50.7 \%) \\
35(55.6 \%) \\
22(38.6 \%)\end{array}$ & 0.001 \\
\hline
\end{tabular}

$* \mathbf{P}$-value $\leq \mathbf{0 . 0 5}$ is considered statistically significant 
Table 2: Mean scores of Pain and fatigue

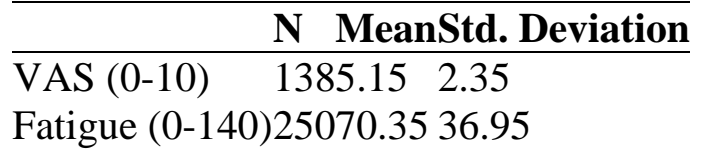

Table 3: Frequency of characters of pain

\begin{tabular}{llrll}
\hline & None & Mild & Moderate & Severe \\
\hline Throbbing pain & $61(44.2 \%)$ & $38(27.5 \%)$ & $32(23.2 \%)$ & $7(5.1 \%)$ \\
Shooting pain & $81(58.7 \%)$ & $27(19.6 \%)$ & $25(18.1 \%)$ & $5(3.6 \%)$ \\
Stabbing pain & $74(53.6 \%)$ & $25(18.1 \%)$ & $25(18.1 \%)$ & $14(10.1 \%)$ \\
Sharp pain & $77(55.8 \%)$ & $22(15.9 \%)$ & $29(21.0 \%)$ & $10(7.2 \%)$ \\
Cramping pain & $66(47.8 \%)$ & $34(24.6 \%)$ & $28(20.3 \%)$ & $10(7.2 \%)$ \\
Gnawing pain & $93(67.4 \%)$ & $25(18.1 \%)$ & $15(10.9 \%)$ & $5(3.6 \%)$ \\
Burning pain & $81(58.7 \%)$ & $30(21.7 \%)$ & $20(14.5 \%)$ & $7(5.1 \%)$ \\
Aching pain & $70(50.7 \%)$ & $25(18.1 \%)$ & $36(26.1 \%)$ & $7(5.1 \%)$ \\
Heavy pain & $70(50.7 \%)$ & $25(18.1 \%)$ & $36(26.1 \%)$ & $7(5.1 \%)$ \\
Tender pain & $49(35.5 \%)$ & $31(22.5 \%)$ & $45(32.6 \%)$ & $13(9.4 \%)$ \\
Splitting pain & $86(62.3 \%)$ & $26(18.8 \%)$ & $19(13.8 \%)$ & $7(5.1 \%)$ \\
Exhausting pain & $49(35.5 \%)$ & $32(23.2 \%)$ & $37(26.8 \%)$ & $20(14.5 \%)$ \\
Sickening pain & $93(67.4 \%)$ & $24(17.4 \%)$ & $15(10.9 \%)$ & $6(4.3 \%)$ \\
Fearful pain & $80(58.0 \%)$ & $28(20.3 \%)$ & $18(13.0 \%)$ & $12(8.7 \%)$ \\
Cruel pain & $85(61.6 \%)$ & $24(17.4 \%)$ & $22(15.9 \%)$ & $7(5.1 \%)$ \\
\hline
\end{tabular}

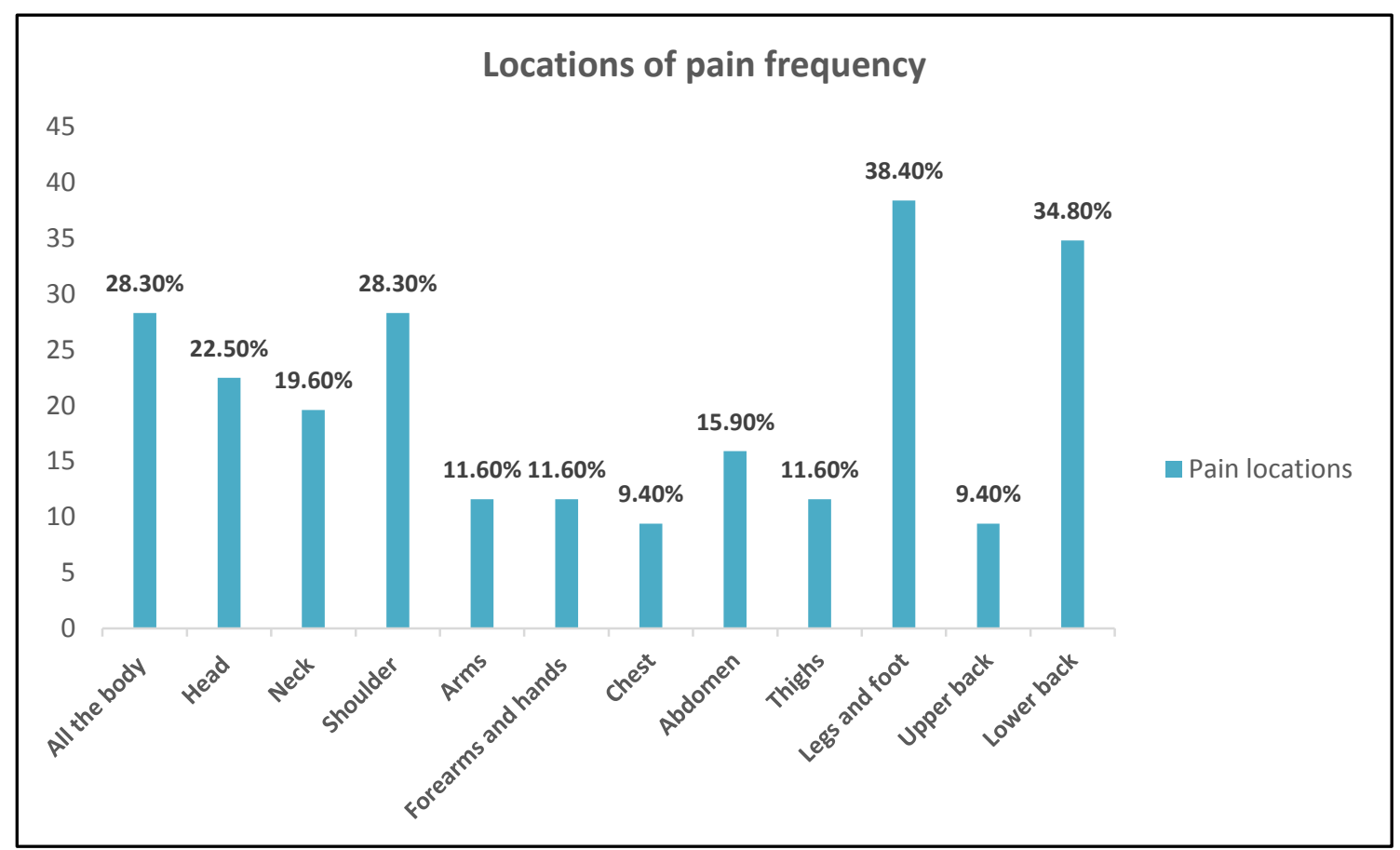

Figure 1: Pain location 


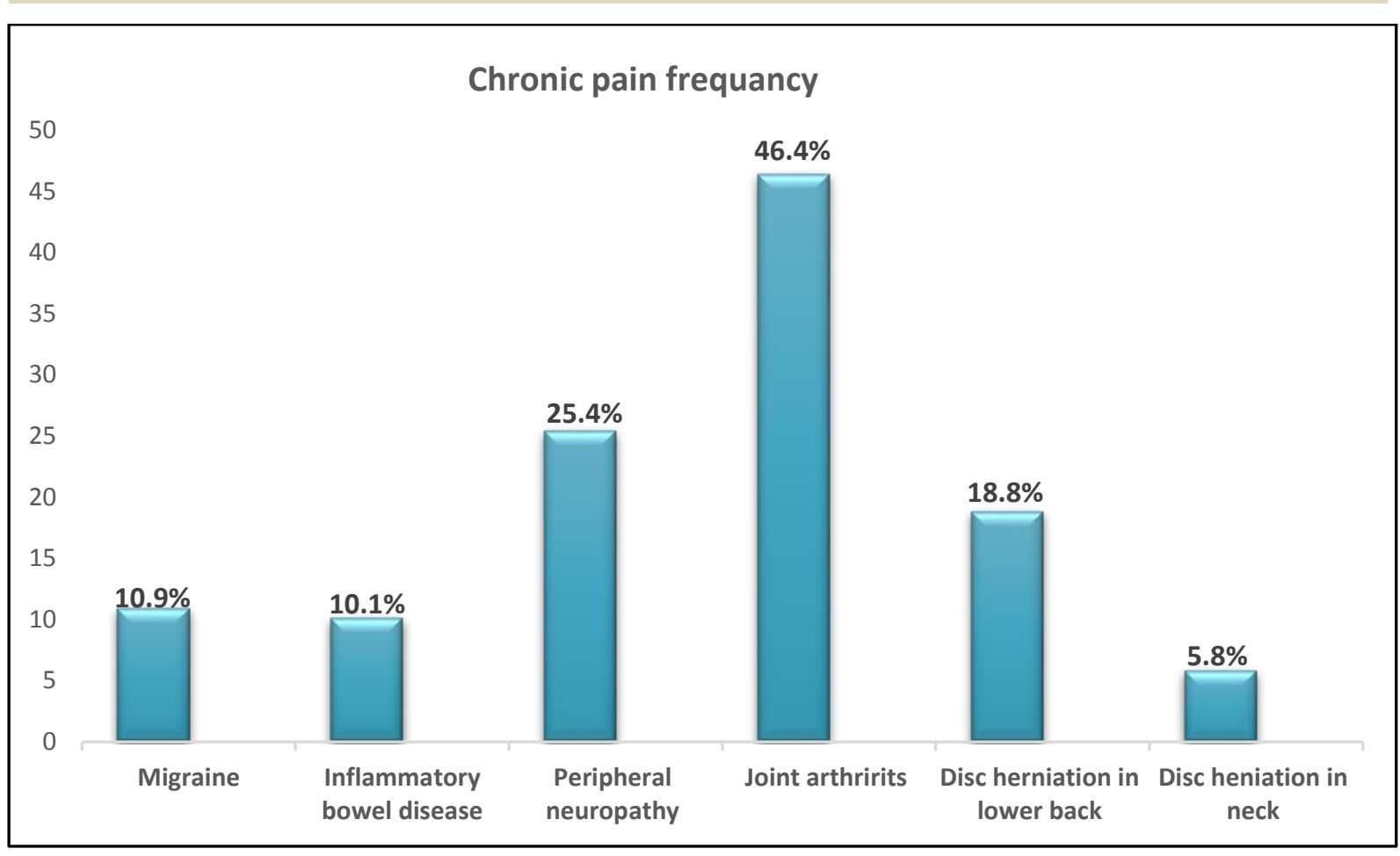

Figure 2: Chronic pain

\section{DISCUSSION:}

DM has a worrying increasing rate among Saudi population; approximately 7 million people are diabetic, and approximately 3 million people are pre-diabetic (17). This large prevalence results in related diabetes complaints such as fatigue and pain.

Half of our diabetic patients have pain (55.2\%). This is similar to what has been determined in two different studies, which showed that approximately $70 \%$ of their cohort had pain (16 ) (8). Furthermore, changes in the connective tissue properties in diabetics increase the risk of different neuromuscular pain including the lower back pain (18).

The abovementioned results are consistent with the results of this study, which suggested that leg and foot pain, followed by pain in lower back, shoulders, and whole body were most frequently encountered in diabetics. Similarly, recently published data by Aldossari KK et al. (14) have also reported that lower limb and back pain was most prevalent in their study group. The VAS score in our study was 5.15 and was considered moderate in severity, as explained by Boonstra AM et al. (19).

Regarding chronic pain, most of our patients exhibited joint arthritis (46.40\%) followed by peripheral neuropathy and disc herniation in the lower back, i.e., $25.40 \%$ and $18.80 \%$, respectively; however, the recently published data by Aldossari KK et al. showed that lower limb and back pain was most prevalent in their study group; however, this was not specifically determined because arthritis could be the source of pain (14).

The mean score of fatigue in our study was 70.35 ( $\mathrm{SD}=36.95)$. This is considered high compared to the score in a study performed in Netherland (i.e., 45.9). We do not know the exact 
reason for this; however, the higher proportion of co-morbidities in our study may partially explain this increased score (8).

No association was observed between the type of diabetes and fatigue in our study. However, in Norway, fatigue was significantly associated with type 1 diabetes (20). This result was obtained possibly because a different questionnaire was used in the Norway study. The longer duration of diabetes and being female are strongly associated with pain, as has been described in different studies $(8,21)$.

In contrast to our study, pain has been associated with the level of $\mathrm{HbA1c}$ in the study conducted in the USA; this result may be related to the methods used in the abovementioned study, which gave them more accurate results than ours (16) . Compared to our study, Menting $\mathbf{J}$ et al. have shown that there is no correlation between aging and pain (8); various lifestyles and cultures may be the cause for this difference.

Neuropsychiatric symptoms (i.e., anxiety and depression) were determined to be associated with pain in different studies $(8,22)$. Anxiety was determined to be significantly associated with pain in our study. People complaining of pain are usually less physically active. The more physical activity that people perform, the higher is their pain tolerance (23). This was shown well in our study because there was significant association between pain and physical activity, which was similar to the results obtained by M. J. Bair et al. (16).

Moreover, hypertension was the most common DM comorbidity in our study (29.2\%). This association between DM and hypertension is well-known. This association is likely due to the role of the adrenergic system in the pathogenesis of both DM and hypertension (24).

Retinopathy and neuropathy as diabetes-related complications are the predominantly reported complications in our patients. They are both strongly associated. Neuroretinal nerve fiber dysfunction has been noted with the presence of neuropathy (25).

Regarding the pain characters, our study determined that throbbing pain, shooting pain, cramping pain, aching pain, and burning pain were significantly associated with the HbA1c level. Diabetic neuropathic pain is usually characterized by tingling, burning, sharp, shooting, lancinating, or electrical sensation $(26,27)$.

In our study, painkillers were used by $84.4 \%$ of diabetics. Because pain affects the quality of life, long-term use of painkillers (including opioids) has been shown in a higher proportion of patients with diabetes (28).

Our study was limited by small sample size and lack of clinical assessment of the patients. Future studies are needed to evaluate a larger sample size of diabetic patients using physical examination.

\section{CONCLUSION:}


In conclusion, pain is a highly prevalent symptom in diabetic patients. It is strongly related to age, gender, anxiety, depression, and physical activity. Regular follow-up for diabetic patients is recommended to evaluate the degree of disease control by looking for potential complications. Thus, our study highlights the importance of assessing and preventing pain in diabetic patients.

\section{ACKNOWLEDGEMENTS:}

The authors would like to thank Falcon Scientific Editing (https://falconediting.com) for proofreading the English language in this paper.

\section{REFERENCES}

1. Fact sheets. Resources \& publications. Diabetes. CDC [internet]. https://Wwwcdcgov/diabetes/library/factsheetshtml\#about . 2020.

2. WHO. Diabetes. https://www.who.int/

3. Alqurashi KA, Aljabri KS, Bokhari SA. Prevalence of diabetes mellitus in a Saudi community. Annals of Saudi medicine. 2011;31(1):1923. https://www.ncbi.nlm.nih.gov/pubmed/21245594. doi: 10.4103/02564947.75773.

4. Kroenke K, Mangelsdorff AD. Common symptoms in ambulatory care: Incidence, evaluation, therapy, and outcome. The American journal of medicine. 1989;86(1):262-266. http://dx.doi.org/10.1016/0002-9343(89)90293-3. doi: 10.1016/0002-9343(89)90293-3.

5. Kroenke K, Price RK. Symptoms in the community: Prevalence, classification, and psychiatric comorbidity. Archives of internal medicine (1960). 1993; 153(21):2474 2480. http://dx.doi.org/10.1001/archinte.1993.00410210102011. doi:10.1001/archinte.1993.00410210102011.

6. Arrington ME, Mangelsdorff AD. The prevalence of symptoms in medical outpatients and the adequacy of therapy. Archives of internal medicine (1960). 1990;150(8):1685-

1689. http://dx.doi.org/10.1001/archinte.1990.00040031685016.

doi: 10.1001/archinte.1990.00040031685016.

7. Goedendorp MM, Tack CJJ, Steggink E, Bloot L, Bazelmans E, Knoop H. Chronic fatigue in type 1 diabetes: Highly prevalent but not explained by hyperglycemia or glucose variability. Diabetes $\quad$ care. 2014; 37(1):7380. https://www.narcis.nl/publication/RecordID/oai:repository.ubn.ru.nl:2066\%2 F127562. doi: 10.2337/dc13-0515. 
8. Menting J, Tack CJ, Knoop H. Prevalence and correlates of pain in fatigued patients with type 1 diabetes. Journal of psychosomatic research. 2017;95:6873. https://www.clinicalkey.es/playcontent/1-s2.0-S0022399917301502. doi: 10.1016/j.jpsychores.2017.02.010.

9. BENBOW SJ, WALLYMAHMED ME, MACFARLANE IA. Diabetic peripheral neuropathy and quality of life. QJM : monthly journal of the Association of Physicians. 1998;91(11):733-

737. https://www.ncbi.nlm.nih.gov/pubmed/10024935.

doi: 10.1093/qjmed/91.11.733.

10. Galer BS, Gianas A, Jensen MP. Painful diabetic polyneuropathy: Epidemiology, pain description, and quality of life. Diabetes research and clinical practice. 2000;47(2):123-128. http://dx.doi.org/10.1016/S0168-8227(99)00112-6. doi: 10.1016/S0168-8227(99)00112-6.

11. Gore M, Brandenburg NA, Dukes E, Hoffman DL, Tai K, Stacey B. Pain severity in diabetic peripheral neuropathy is associated with patient functioning, symptom levels of anxiety and depression, and sleep. Journal of pain and symptom management. 2005;30(4):374-

385. http://dx.doi.org/10.1016/j.jpainsymman.2005.04.009.

doi: 10.1016/j.jpainsymman.2005.04.009.

12. Turk DC. The role of psychological factors in chronic pain. Acta anaesthesiologica Scandinavica. 1999;43(9):885888. http://www.ingentaconnect.com/content/mksg/aas/1999/00000043/00000009 /art00003. doi: 10.1034/j.1399-6576.1999.430904.x.

13. Fritschi C, Quinn L. Fatigue in patients with diabetes: A review. Journal of psychosomatic research. 2010;69(1):33-

41. https://www.clinicalkey.es/playcontent/1-s2.0-S0022399910000620. doi: 10.1016/j.jpsychores.2010.01.021.

14. Aldossari KK, Shubair MM, Al-Zahrani J, et al. Association between chronic pain and diabetes/prediabetes: A population-based cross-sectional survey in Saudi arabia.Pain research \& management. 2020;2020:16. https://dx.doi.org/10.1155/2020/8239474. doi: 10.1155/2020/8239474.

15. El-Metwally A, Shaikh Q, Aldiab A, et al. The prevalence of chronic pain and its associated factors among saudi al-kharj population; a cross sectional study. BMC musculoskeletal disorders. 2019;20(1):177. https://www.ncbi.nlm.nih.gov/pubmed/31027485. doi: 10.1186/s12891-019-2555-7. 
16. Bair MJ, Brizendine EJ, Ackermann RT, Shen C, Kroenke K, Marrero DG. Prevalence of pain and association with quality of life, depression and glycaemic control in patients with diabetes. Diabetic medicine. 2010;27(5):578584. https://onlinelibrary.wiley.com/doi/abs/10.1111/j.1464-5491.2010.02971.x. doi: 10.1111/j.1464-5491.2010.02971.x.

17. Mohamed Abdulaziz Al Dawish, Asirvatham Alwin Robert, Rim Braham, et al. Diabetes mellitus in Saudi Arabia: A review of the recent literature. Current diabetes reviews. 2016;12(4):359368. http://www.eurekaselect.com/openurl/content.php?genre=article\&issn=1573 $-3998 \&$ volume $=12 \&$ issue $=4 \&$ spage $=359$. doi: $10.2174 / 1573399811666150724095130$.

18. HELIOVAARA M, MAKELA M, KNEKT P, IMPIVAARA O, AROMAA A. Determinants of sciatica and low-back pain. Spine (Philadelphia, Pa. 1976). 1991;16(6):608-614. https://www.ncbi.nlm.nih.gov/pubmed/1830689. doi: 10.1097/00007632-199106000-00002.

19. Boonstra AM, Schiphorst Preuper HR, Balk GA, Stewart RE. Cut-off points for mild, moderate, and severe pain on the visual analogue scale for pain in patients with chronic musculoskeletal pain. Pain (Amsterdam). 2014;155(12):25452550. http://dx.doi.org/10.1016/j.pain.2014.09.014.

doi: 10.1016/j.pain.2014.09.014.

20. Jensen $\varnothing$, Bernklev T, Gibbs C, Moe RB, Hofsø D, Jelsness-Jørgensen L. Fatigue in type 1 diabetes, prevalence, predictors and comparison with the background population. Diabetes research and clinical practice. 2018;143:7178. http://dx.doi.org/10.1016/j.diabres.2018.06.012. doi: 10.1016/j.diabres.2018.06.012.

21. Pieretti S, di giannuario A, di giovannandrea $\mathrm{R}$, marzoli $\mathrm{F}$, piccaro $\mathrm{G}$, minosi $\mathrm{P}$, et al. quality of life in mental health services with a focus on psychiatric rehabilitation practice. ann ist super sanità. 2016;52(2):184-9. .

22. HENRIQUES, alexandre annes. depression and pain. rev. bras. psiquiatr. [online]. 2013, vol.35, n.1 .

23. JONES M, BOOTH J, TAYLOR J, BARRY B. Aerobic training increases pain tolerance in healthy individuals. Medicine and science in sports and exercise. 2014;46(8):1640-1647. https://www.ncbi.nlm.nih.gov/pubmed/24504426. doi: 10.1249/MSS.0000000000000273.

24. Cryer MJ, Horani T, DiPette DJ. Diabetes and hypertension: A comparative review of current guidelines. The journal of clinical hypertension (Greenwich, Conn.). 
2016;18(2):95-100. https://onlinelibrary.wiley.com/doi/abs/10.1111/jch.12638. doi: $10.1111 /$ jch.12638.

25. Neriyanuri S, Pardhan S, Gella L, et al. Retinal sensitivity changes associated with diabetic neuropathy in the absence of diabetic retinopathy. British journal of ophthalmology. 2017;101(9):1174-1178. http://dx.doi.org/10.1136/bjophthalmol2016-309641. doi: 10.1136/bjophthalmol-2016-309641.

26. TESFAYE S, BOULTON AJM, DICKENSON AH. Mechanisms and management of diabetic painful distal symmetrical polyneuropathy. Diabetes care. 2013;36(9):2456-2465. https://www.ncbi.nlm.nih.gov/pubmed/23970715. doi: $10.2337 / \mathrm{dc} 12-1964$.

27. Bansal V, Kalita J, Misra UK. Diabetic neuropathy. Postgraduate medical journal. 2006;82(964):95-100. http://dx.doi.org/10.1136/pgmj.2005.036137. doi: 10.1136/pgmj.2005.036137.

28. Ng BP, Rabold EM, Guy GP, Park C, Zhang P, Smith BD. Opioid dispensing among adult Medicaid enrollees by diabetes status. Current medical research and opinion. 2020;36(10):15771581. http://www.tandfonline.com/doi/abs/10.1080/03007995.2020.1815687. doi: 10.1080/03007995.2020.1815687.

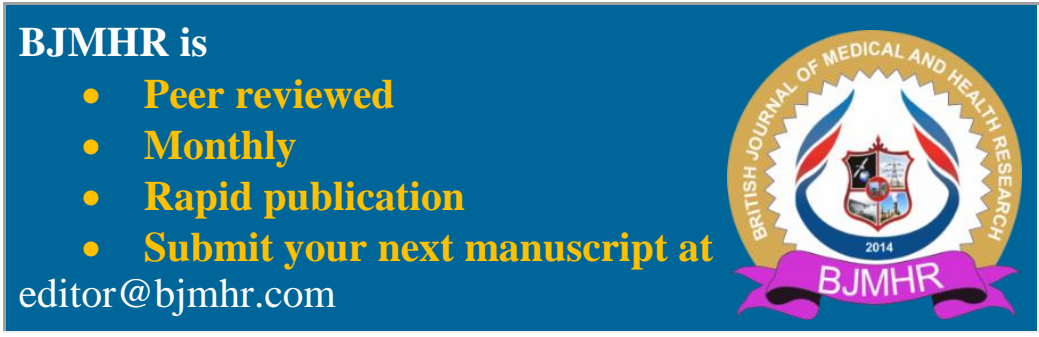

